\title{
The Effect of Alum as Filter Conditioner on the Performance of Conventional Rapid Sand Filter
}

\author{
M. H. Mota, P.S. Patil
}

\begin{abstract}
Filtration is a one of the most important and critical unit process followed worldwide which removes dirt particles from water. As the water quality standards are changing and becoming more stringent, the improvement in the performance of existing rapid sand filters is unavoidable. The use of filter conditioning to improve filter performance is a relatively recent development in drinking water treatment. Different advantages claimed by such use of filter aid includes lessening ripening period, superior turbidity removal and relatively stable filtrate quality. It also has limitations like reduction in filter run and comparatively higher back washing requirement. To assess the suitability of such method,under the existing conditions is of enormous importance. ${ }^{12}$

Current research explains the impact of filter media conditioning on the overall performance of conventional rapid sand filter. The study was carried out by installing a pilot plant at Ichalkaranji municipal water treatment plant. Different doses of alum as filter conditioner were tested and the comparison was made with the performance of conventional filter without filter aid. The parameters for evaluation were turbidity removal, filter run and backwash requirements. The dose of alum as filter conditioner was given as slug dose. The effect of zeta ( $\zeta$ ) potential change was observed to be one of the major reasons of the performance improvement, accelerating the surface removal since initial phase.
\end{abstract}

Key words:backwash requirement,media conditioning,rapid

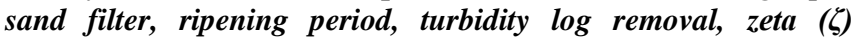
potential.

\section{INTRODUCTION}

Filtration is a unit process which physically removes suspended materials, certain amount of bacteria and viruses, which are able to pass through processes like aeration and clarification. The filtration using granular media in the form of rapid sand filter is supposed to be the polishing stage of the water treatment process. Thus the ultimate quality of water produced by any WTP is largely affected by the performance of the filters. The government is trying very hard to improve the water quality to be supplied, by enforcing the stringent changes in water quality standards.[1]

Revised Manuscript Received on February 05, 2020.

* Correspondence Author

* Mr. Manoj H Mota, Research scholar, Rajarambapu Institute of Technology, Rajararamnagar, Islampur Assistant professor, Civil Engineering,Sharad Institute of Technology, College of Engineering, Yadrav. India Email: mhmota77@gmail.com

Dr. P S Patil, Professor, Civil Engineering, Rajarambapu Institute of Technology, Rajararamnagar, Islampur India

Email:Pandurang.patil@ritindia.edu

(C) The Authors. Published by Blue Eyes Intelligence Engineering and

Sciences Publication (BEIESP). This is an open access article under the CC BY-NC-ND license (http://creativecommons.org/licenses/by-nc-nd/4.0/)
On the other hand most of the water treatment plants in India are facing the problems like substandard overall performance and unsatisfactory water supply besides unsatisfactory operation and maintenance. The water quality is generally worst during the monsoon period. Changed water quality standards have increased their problems in multifold. The proper understanding of the behavior of the existing filter behavior and implementing the corrective measures, with minimum process change holds the key under such situations, in most of the developing countries like India. In developed countries different procedures have been reported to be very significant in improving overall filter performance. Few of such procedures includes filter to waste strategy, filter resting, slow start, extended terminal sub-fluidization wash, addition of polymer or coagulant in wash water or use of filter aid in influent etc. [2],[3],[4],[5],[6],[7],[8],[9],[10] Few researches have even advocated up-flow filtration as a method to improve the performance [11]. The assessment of suitability of such methods can be one of the major objectives of research in the field of water treatment in India. The research explained in this paper, unfoldsone such study made, to improve the performance of rapid sand filter in terms of better effluent quality, by using the alum as filter conditioner. The method is very easy to implement with no change in existing physical dimensions of filter box. The study was carried out by installing a pilot plant at Ichalkaranji municipal water treatment plant. Different doses of alum as filter aid were tested and the comparison was made with the performance of conventional filter without filter aid. The parameters for evaluation were turbidity removal, filter run and backwash requirements. The quality of water was improved dramatically and the residual turbidity was reduced in the range of 'less than 1 NTU'. The reason behind the improved removal of turbidity was found to be modified surface charge. Filter conditioning has also resulted in rapid headloss development, smaller filtration cycle and increased back-washing requirement. The method is also useful in restricting the entry of bacteria and viruses by certain extent [12] The zeta $(\zeta)$ potential of granular media, which is negative in normal cases and resulting in limited surface removal in initial phases, was changed to less negative resulting in improved surface removal [13]. This event has also created more opportunities in latter stage of filtration to remove turbidity. Because of changed zeta potential the improved bond between the particles removed from water also resulted in reduction in separation and reduced the chances of possible break through because of higher head loss.

\section{A. Some facts about granular filtration:}

Filtration is a critical process to understand. As commonly misunderstood, it is not a process which merely removes the turbidity causing particles by the process of straining. 
It involves number of complicated processes. The most evident process is the physical straining of particles too large to pass between filter grains. Other processes are also important, since most of the solid material contained in influent is too small to be removed by straining alone.

The removal of suspended particles within a filter is considered to have minimum two sequential steps, one being the transport and the second is attachment. In the former step, the particles are transported from the bulk fluid to the direct surrounding of solid-liquid interface, which may be a grain of the media or to another particle formerly retained in the filter bed. Particle attachment to the media is thought to be dominated by electrical and chemical interactions such as electrostatic attraction or repulsion within the electrical double layer and van-der Waals attractive forces that act between particles and surfaces at short distances [14],[15].

\section{B. Operational cycle of filtration:}

During the normal operational cycle of conventional rapid filtration, three phases can be distinguished:

(1) A ripening or maturating stage is the initial phase which occurs at the beginning of the filter run. It is characterized by low head loss and less particle removal. The length of the ripening period in rapid sand filters depends on the backwash procedure, influent characteristics, and backwash water chemistry as well as factors like amount and characteristics of remnant particles [4]. It may last from few minutes to several hours [18],[19].The insufficient removal of pathogenic microorganisms can be safely attributed to this stage [20].

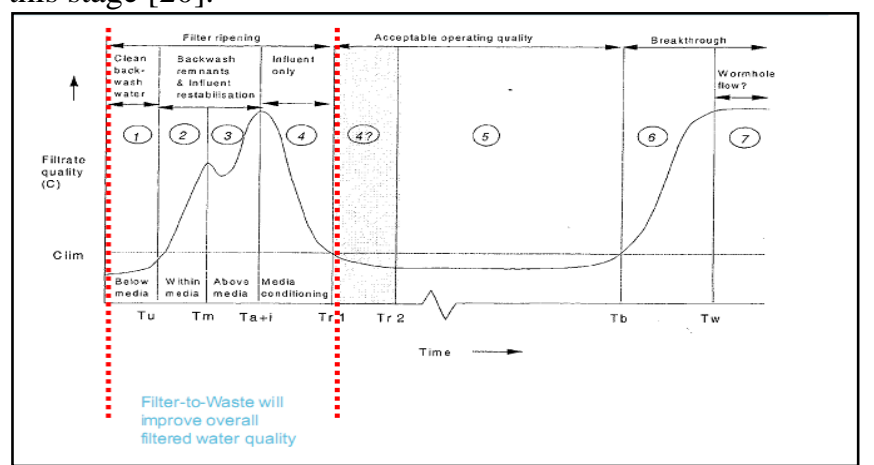

Fig 1: Typical filter run, particle count and turbidity [19]

(2) A working stage, which occurs after the ripening, the filter performance is most excellent in terms of removal of turbidity. The head loss during this stage gradually increases due to incremental clogging of filter media. The head loss is the function of grain density, bed porosity and sphericity of the filter media.

(3) A breakthrough stage, is the final phase, during which turbidity removal gradually reduces and the head loss accumulates rapidly, affecting the filtration rate as well as filtrate quality. . Typical head loss in conventional RSF is around $2.5 \mathrm{~m}$ to $3 \mathrm{~m}$.

\section{Effect of humic substances present in water:}

Most of the water treatment plants in India are depending on the rivers, as source. Agriculture, the major occupation in India, is practiced on the banks of these rivers. These agricultural activities are resulting in large run-off, rich in humic substances. These humic substances are reported to affect the performance of porous granular medium filters adversely by reducing particle capture. Dissolved aquatic humic substances, which are net negatively charged macromolecules, can adsorb onto the surface of turbidity causing clay particles,further increasing their negative charge [21],[22] ultimately resulting in reduced removal. Because of such complexities, the assessment of any modification for performance improvement is very essential.

\section{MATERIAL AND METHODS:}

The sand utilized for the filter media was obtained from the stock sand available at Ichalkaranji WTP. The required sand was initially washed and sun dried. The sand of desired specification was prepared by sieving and mixing in appropriate proportions. The fines from sand were removed by washing out. The coefficient of uniformity of sand media prepared was 1.7 , effective size was $0.6 \mathrm{~mm}$ while the specific gravity was 2.68 .

The researchwas carried out at existing water treatment plant located at Ichalkaranji. The pilot model having two square filter columns of size $15 \mathrm{~cm}$ and height of $1.8 \mathrm{~m}$ was used [23]. One column was acted as a control unit while second column was acted as experimental column. The essential piping and valves were installed for proper control on filtration rate and to achieve the back washing. The clarified water was used to challenge both filters. The turbidity of clarified water used was in the range of 5 to 6 NTU.The help of pump of $0.5 \mathrm{HP}$ capacity was taken to accomplish back washing. The backwashing rate was kept as $0.7 \mathrm{~m} / \mathrm{min}$.

The alum was added to condition the media. It was added as a slug dose, after backwashing, just before challenging the filter column. Different alum doses tried during the study are mentioned in table 1.

Table 1: different dosages of alum as media conditioner

\begin{tabular}{|r|c|c|c|}
\hline $\begin{array}{r}\text { Sr. } \\
\text { No. }\end{array}$ & Alum dose & $\begin{array}{c}\text { Normalized rate of } \\
\text { alum addition* per } \\
\text { unit filter area }\end{array}$ & $\begin{array}{c}\text { Moles of } \\
\text { Alum added } \\
\text { per unit filter } \\
\text { area }\end{array}$ \\
\hline 01. & $\begin{array}{c}5 \% \text { alum } \\
\text { solution...1 lit }\end{array}$ & $2.222 \mathrm{~kg} / \mathrm{m}^{2}$ & 3.4 \\
\hline 02. & $\begin{array}{c}2.5 \% \text { alum } \\
\text { solution...0.5 lit }\end{array}$ & $0.555 \mathrm{~kg} / \mathrm{m}^{2}$ & 0.85 \\
\hline 03. & $\begin{array}{c}1 \% \text { alum } \\
\text { solution...1lit }\end{array}$ & $0.444 \mathrm{~kg} / \mathrm{m}^{2}$ & 0.68 \\
\hline
\end{tabular}

* Rate of alum addition $\left(\mathrm{kg} / \mathrm{m}^{3}\right)$ = Strength X Quantity of solution / (0.15 X 0.15)

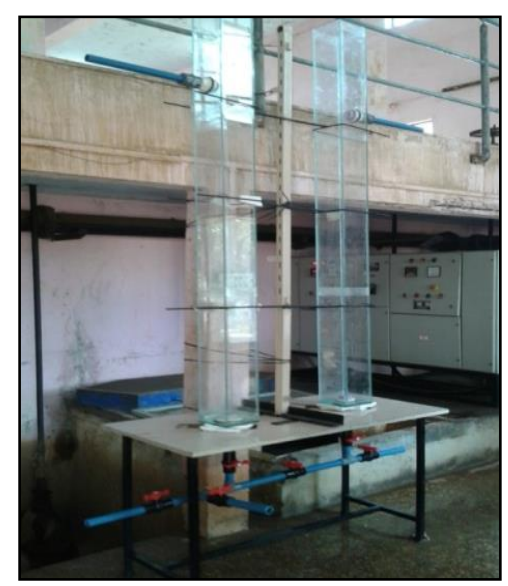

Fig.2Photograph of installed pilot plant at Ichalkaranji WTP 
The turbidity of filter inlet as well as outlet was measured initially at an interval of 1minute unless the acceptable water quality was produced and afterwards every 15 minutes till the end of filter run.The nephelometer was used to measure the turbidity.

As per the BIS (IS 10500) the acceptable limit of turbidity was assumed to be 5NTU. Turbidity removal efficiency is expressed in terms of $\boldsymbol{p} \boldsymbol{C}^{*}$ in which, ' $\boldsymbol{C}^{*}$ ' is the turbidity of the filter effluent water in NTU normalized by the turbidity of the influent water and ' $p$ ' is the negative logarithm.
Mathematically $p C^{*}=-\log \left(C_{\text {effluent }} / C\right.$ influent $)$. It is usually referred as 'log removal' in similar research. Higher value of $p C^{*}$ indicates better performance.

\section{RESULTS AND DISCUSSIONS:}

Table 2 summarizes the observations recorded during the pilot scaled research.

Table 2: Summery of observations recorded

\begin{tabular}{|c|c|c|c|c|c|c|c|c|c|}
\hline \multirow[t]{2}{*}{$\begin{array}{l}\text { Sr. } \\
\text { No. }\end{array}$} & \multirow{2}{*}{$\begin{array}{c}\text { Alum } \\
\text { Dose } \\
(\text { moles } \\
\left.\text { per } \mathbf{m}^{2}\right)\end{array}$} & \multicolumn{2}{|c|}{ Filter run (min) } & \multicolumn{2}{|c|}{ Ripening period (min) } & \multicolumn{2}{|c|}{$\begin{array}{l}\text { Mean filtrate turbidity } \\
\text { (NTU) }\end{array}$} & \multicolumn{2}{|c|}{$\begin{array}{l}\text { Backwashing water } \\
\text { required (lit) }\end{array}$} \\
\hline & & $\begin{array}{l}\text { Conditioned } \\
\text { filter }\end{array}$ & $\begin{array}{c}\text { Conventional } \\
\text { filter }\end{array}$ & $\begin{array}{l}\text { Conditioned } \\
\text { filter }\end{array}$ & $\begin{array}{c}\text { Conventional } \\
\text { filter }\end{array}$ & $\begin{array}{l}\text { Conditioned } \\
\text { filter }\end{array}$ & $\begin{array}{c}\text { Conventional } \\
\text { filter }\end{array}$ & $\begin{array}{l}\text { Conditioned } \\
\text { filter }\end{array}$ & $\begin{array}{c}\text { Conventional } \\
\text { filter }\end{array}$ \\
\hline 01 & 3.4 & 630 & 790 & 2 & 17 & 3.5 & 0.5 & 455 & 360 \\
\hline 02 & 0.85 & 630 & 767 & 3 & 17 & 3.6 & 0.5 & 435 & 350 \\
\hline 03 & 0.68 & 660 & 777 & 5 & 18 & 3.9 & 3.5 & 370 & 360 \\
\hline
\end{tabular}

The initial turbidity spike was observed as a result of discharge of remnant particles, confirming the findings of previous researches [24]. The behavior of the filter was very poor in the ripening period. But the ripening period was significantly reduced in case of filter conditioning. The behavior of conventional rapid sand filter and conditioned media is presented in fig. no.3

During complete filter run, the effluent quality of conditioned media was much stable and superior as compared to conventional filter media. The mean filtrate turbidity was found in the range of $0.5 \mathrm{NTU}$, which was a really incredible in terms of performance improvement. It was also observed that the alum aided filter run was ended because of excessive head loss and choking of the media, which was expected because of high turbidity removal and rapid filling of voids by the removal of turbidity causing particles. Fig. 2 shows the performance comparison in terms of $\mathbf{p} \mathbf{C}^{*}$. It is quite clear that the conditioned media has resulted in producing the high quality water with mean turbidity in the range of $0.5 \mathrm{NTU}$.

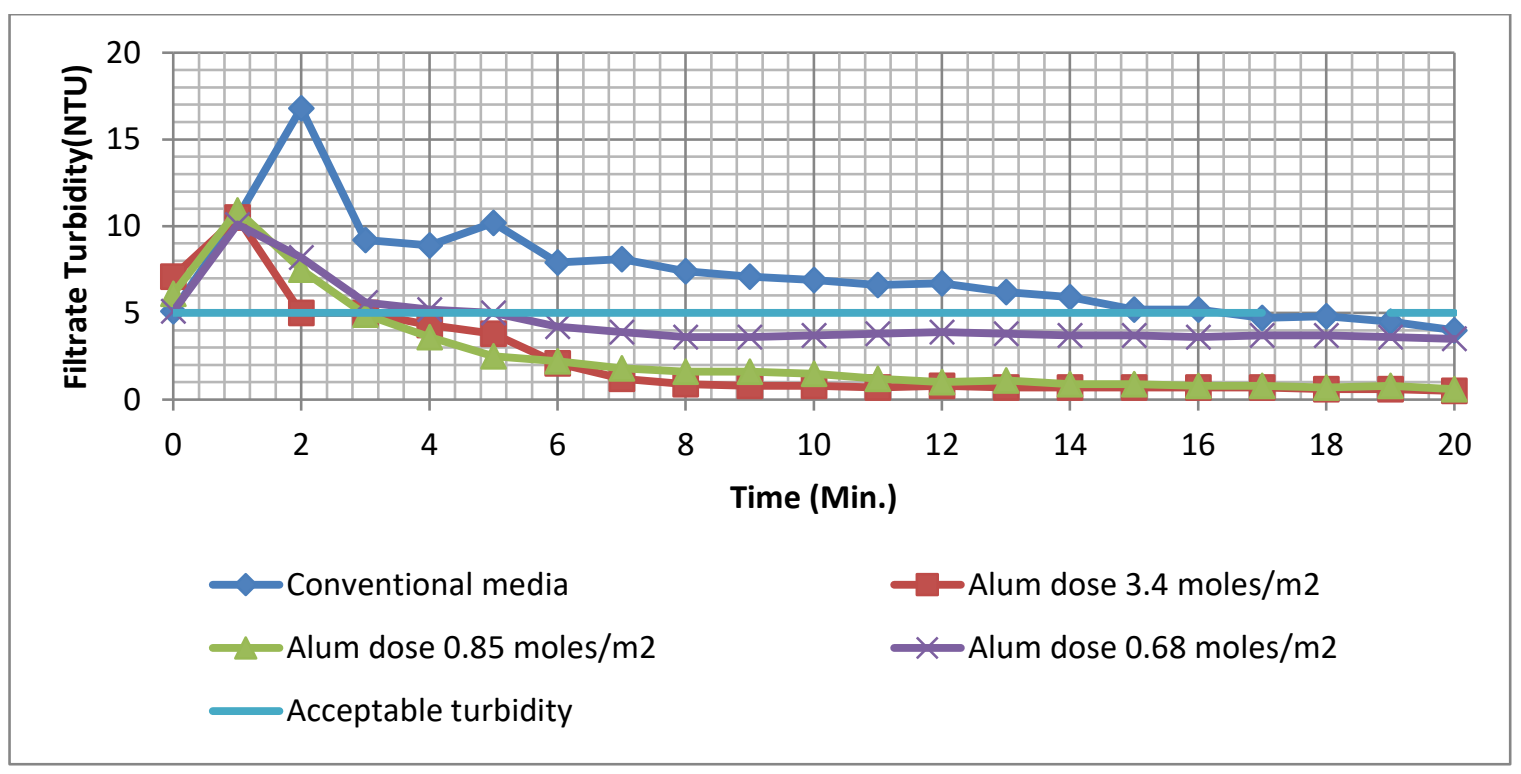

Fig.3. Ripening behavior of conventional media v/s Conditioned media 


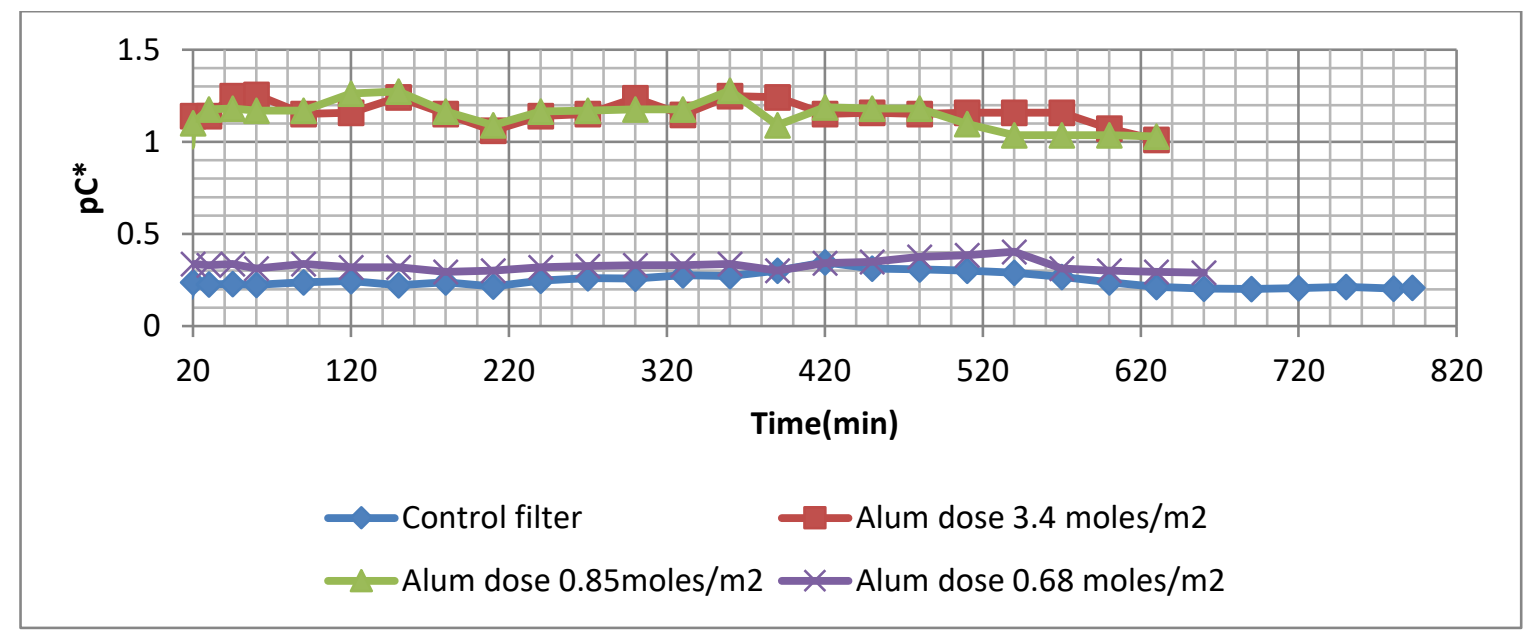

Fig.4 Turbidity removal efficiency of conventional media v/s conditioned media

\section{EFFECT OF ZETA (ZP) POTENTIAL:}

The most common pollutants present in water areparticulate contaminants as well as pathogens. These impurities are primarily negatively charged. The bacteria and viruses also carry negative charge. Such elements are always undesirable as they are difficult to separate because of such charge. These particles can be removed by oppositely charged additives by reducing their charge close to zero. Zeta $\left(\zeta_{\mathrm{p}}\right)$ potential is nothing but the measure of such potential. Higher zeta $\left(\zeta_{\mathrm{p}}\right)$ potential indicates more repulsion of the particles. The addition of coagulant like alum destabilizes the particles by reducing the negative zeta $\left(\zeta_{\mathrm{p}}\right)$ potential (Bean et.al.1964).

On other hand the sand media is also negatively charge resulting in less efficiency because of repulsing the particles. Influent particles with negative zeta $\left(\zeta_{\mathrm{p}}\right)$ potential are less likely to adhere to negatively charged sand grains unless their zeta $\left(\zeta_{\mathrm{p}}\right)$ potential is modified. Excess doses of coagulant are required for reversing the surface charge to positive or less negative. So the attempt is made to modify the surface charge of media by conditioning it with alum. Also the formation of the coat of liquid alum around the sand grains, resulted in suppression of repulsive forces of media and particles present in the influent.

The $\operatorname{zeta}\left(\zeta_{\mathrm{p}}\right)$ potential of influent was measured and found in the range of -17.8 to $-20.1 \mathrm{mV}$, while the $\operatorname{zeta}\left(\zeta_{\mathrm{p}}\right)$ potential of effluent passed through the conditioned media was found in the range of $-3.0 \mathrm{mV}$ to $-11.8 \mathrm{mV}$ during the ripening phase, depending on the dose of alum. Higher $\operatorname{zeta}\left(\zeta_{\mathrm{p}}\right)$ potential is observed in case of high alum dose as conditioner. The zeta $\left(\zeta_{\mathrm{p}}\right)$ potential is decreased as the dose of alum is decreased. Still for various dosages examined the reduction in $\operatorname{zeta}\left(\zeta_{\mathrm{p}}\right)$ potential was proved to be significant. This is a fair indication of excellent surface removal of particles after the conditioning because of destabilization. Additionally because of contact of influent particles with the alum solution present in the pores may resulting in the destabilization of the particles at less negative zeta $\left(\zeta_{\mathrm{p}}\right)$ potential, improves their settling within the filter media which are acting as a tiny settling basins. Better attachment of particles may even result in increased stress on backwashing process. These particles themselves have created more opportunities in latter phase i.e. working stage to perform much better as compared to control filter. The improved bonding between the conditioned media and particles separated can be also responsible to withstand the shearing effect of water flowing through the pores as well as pressure created by supernatant water and not allowing the break through to occur.

On other hand the better bonding between the particles with the media has also affected the detachment process during the backwashing. The backwashing became little difficult and resulted in higher backwash water consumption.

Table 3: Relation between stability behavior and zeta $\left(\zeta_{\mathrm{p}}\right)$ potential values

\begin{tabular}{|c|c|c|}
\hline Sr. No. & Stability Characteristics & Zeta $\left(\zeta_{\mathrm{p}}\right)$ potential \\
\hline 01. & Maximum agglomeration & +3 to $0 \mathrm{mV}$ \\
\hline 02. & Excellent agglomeration & -1 to $-4 \mathrm{mV}$ \\
\hline 03. & Fair agglomeration & -5 to $-10 \mathrm{mV}$ \\
\hline
\end{tabular}

Source: Zeta meter system 4.0 operating Instructions,[11]

From the recorded observations and fig. 3 and 4 , it is quite clear that the alum aided filtration can be very effective method to improve the performance of conventional rapid sand filters. The overall quality of water produced is far superior as compare to conventional filter, which can result in reduction in the requirement of disinfectant as well.Even a small dose of alum can suppress the ripening period considerably. The dose of 0.68 to 3.4 moles of alum par $\mathrm{m}^{2}$ can improve the filtrate quality radically and result in more than $1 \log$ removal.

It is also the fact that the reduction of filter run as well as rate of filtration will result in less amount of total water production as well as high backwash requirement. The way out to eliminate this problem has to be determined. (It is possible by altering the configuration of media, i.e. by altering the coefficient of uniformity and effective size. Detailed discussion on this is beyond the scope of this paper)

\section{CONCLUSION}

From this research it is quite clear that the media conditioning using alum can be very effective in turbidity removal. 
The alum dose in the range of 0.68 moles to 3.4 moles per $\mathrm{m}^{2}$ of filter media is sufficient in improving the overall turbidity removal efficiency. The overall water quality of filtrate produced is far superior as compare to quality of filtrate produced in case of conventional rapid sand filter. It is in the range of $0.5 \mathrm{NTU}$. Lower dose of alum than 0.68 moles per $\mathrm{m}^{2}$ may not be equally effective.

The major advantage claimed by conditioned media is reduction in ripening period and thus avoiding all associated limitations. The little alum dose in the range of $0.555 \mathrm{~kg} / \mathrm{m}^{2}$ of filter bed area is sufficient in achieving much better filtrate quality. The major reason behind the overall quality improvement can be attributed to modified surface conditions. The zeta potential is reduced and has resulted in improved surface removal since start of filter run. As an outcome of this, the ripening period is considerably reduced. Higher dose of alum resulted in higher reduction in ripening period.

The media conditioning is also resulted in reduction in total filter run and higher backwashing demand thus lowered theoverall water output. Higher dose of media conditioner has reduced the filter run more and also increased the backwashing demand. **These limitations can be addressed by certain measures, mentioned in discussion section. But addressing these limitations is beyond the scope of this paper.

\section{ACKNOWLEDGMENT}

The authors wants to acknowledge the support provided by the Hydraulic engineer, Ichalkaranji Municipal Corporation for permitting the study to carry out in their premise of water treatment plant and Walchand college of Engineering for providing laboratory facility required to complete this research. The authors thank their parent institutes namely Sharad institute of technology, college of Engineering and Rajarambapu Institute of Technology, Rajararamnagar, Islampur without whose support this study would not have been possible.

\section{REFERENCES}

1. IS 10500:2012, Indian standard Drinking water- Specification (second revision)', Bureau of Indian standards, New Delhi,1. 2015

2. Cranston, K.O.,and Amirthrajah, A. "Improving the initial effluent quality of a dual media filter by coagulants in back wash," Journal American Water Works Association, 79(12),1987,p.p. 50-63.

3. Colton, J.F.; Hillis, P.; and Fitzpatrick, C.S.B. 'Filter Backwash and Start-up Strategies for Enhanced Particulate Removal'. Water Research 30(10),1996,p.p.2502-2507

4. Amburgey, J.E.,'Optimization of the Extended Terminal Subfluidization Wash (ETSW) Filter Backwashing Procedure.' Water Research 39,2005, p.p. 314-330.

5. Logsdon, G.S.; Symons, J.M.;Hoye, R.L. \&Arozarena, M.M. 'Alternative Filtration Methods for Removal of Giardia Cysts and Cysts Models'. Journal America Water Works Association, 27(2),1981,p.p. 111

6. Gary S. L., Alan F. H., Michael J. C., John G., Jack L., Claudia H., and John Wi 'Controlling Turbidity Spike with Alum, Iron' .American Water Works Association, Opflow. 2005.

7. Kwok L.C.,'Enhanced Particle Capture in Slow Sand Filters using a Filter Aid', New England water treatment technology assistance center, project summery report.2005

8. Po-Hsun Lin, Leonard W., and Monroe L., 'Post sedimentation Application of Polyaluminum Chloride to Enhance Dual Media Filter Performance,' Journal of Environment Engineering, vol. 139, 612-617. 2013

9. Po-Hsun Lin, Leonard W., and Monroe L., 'Comparison of the Ability of Three Coagulants to Enhance Filter Performance,' Journal of Environment Engineering, vol. 137,2011, p.p. 371-376.
10. Po-Hsun Lin,, Leonard W., and Monroe L., 'Enhanced Particle Capture through Aluminum Hydroxide Addition to Pores in Sand Media, Journal of Environment Engineering, vol. 138,2012, p.p. 8-16.

11. Salkar V.D. and Tembhurkar A.R., "Experimental Evaluation of Ripening Behavior: Down-flow vs. Up-flow Rapid sand Filters", KSCE Journal of Civil Engineering, 20(4), 2016, p.p.1221-1227

12. Owens J., MiltenerR.,Schaefer F. and Rise E. "Pilot scale inactivation of cryptosporidium and Giardia". Proceeding of AWWA WQTC, San Francisco, CA,1994

13. Bean, E.L.," Campbell, and Anspach, F.R.," Zeta Potential measurement in control of coagulation chemical doses" Journal of American Water Works Association, 56(2), 1964, p.p.214-224.

14. Yao, K.M., Habibian, M.T., and O'Melia, C.R, "Water and Waste Water Filtration: Concepts and applications", Environmental Science Technology,5(11).1971, 1105-1112.

15. Pizzi, Nick, 'Optimizing Your Plant's Filter Performance.' Journal America Water Works Association,Op-flow, June 2000. 26(6),2000,p.p. 37-38.

16. Franchi, A., and O'Melia, C. R., "Effects of natural organic matter and solution chemistry on the deposition and re-entrainment of colloids in porous media.” Environmental Science Technology, 37(6),2003,p.p. $1122-1129$

17. Amburgey, J.E., 'Optimization of the Extended Terminal Subfluidization Wash (ETSW) Filter Backwashing Procedure.' Water Research 39, 2005, p.p. 314-330.

18. O'Leary, K ,Eisnor, J, Gagnon and Graham.'Examination of plant performance and filter ripening with particle counters at full-scale water treatment plants.' Journal of Environmental technology. 24.2003,p.p. 1-9.

19. Amburgey, J.E.,'Optimization of the Extended Terminal Subfluidization Wash (ETSW) Filter Backwashing Procedure.' Water Research 39,2005, p.p. 314-330.

20. Suthaker,S. Smith,D. and Stanley,S., 'Optimization of filter ripening sequence.' Aqua, 47,2008, p.p.107-118.

21. Franchi, A., and O'Melia, C. R. "Effects of natural organic matter and solution chemistry on the deposition and re-entrainment of colloids in porous media." Environmental Science Technology, 37(6), 2003, p.p.1122-1129.

22. Pernitsky, D. J., and Edzwald, J. K. "Selection of alum and polyaluminum coagulants: Principles and applications." Journal of Water Supply: Res. Technol.-AQUA, 55(2), 2006, p.p. 121-141

23. Zou R.P and Yu A. B., 'The packing of sphere in a cylindrical container, the thickness effect', Chemical Engineering Science, 50(9), 1995, p.p. 1504-1507.

24. Amirthraj,A and Wetstein,D.P.( 1980), 'Initial degradation of effluent quality during filtration', Journal of American Water works Association, 72(2), 1980, p.p. 518-524

\section{AUTHORS PROFILE}

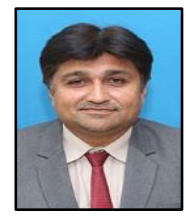

Mr. M.H Mota, is currently working as assistant professor in Department of Civil Engineering of Sharad Institute of Technology, College of Engineering, Yadrav, Ichalkaranji, Maharashtra, India. He has a total teaching experience of more than 18 years and industria experience of 2 years. He has been involved in various live projects currently going on. He is a life member of Indian Society of Technical Education. His research interests are water and waste water treatment and waste management. He has published his research in various reputed peer reviewed journals and conferences. His projects have won various prizes at national level competitions.

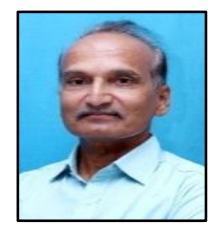

Dr. P. S. Patil, is currently working as Professor \& Head of the Program of Civil, Structural Engineering at K.E. Societies Rajarambapu Institute of technology, Rajaramnagar, Islampur, Maharashtra, India. He has a total teaching Experience of more than 33 Years. He is a member of numerous professional bodies including Institute of Engineers (India), Indian Society of Technical Education, Association of Structural Rehabilitation and Indian Water Resources Society, Roorkee (India). His research areas are structural engineering, Repair and Rehabilitation of structures, and water treatment. He has published his research in various reputed peer reviewed journals and conferences. He has received various awards in various diverse fields for his institutes. He also has fetched a fund of more than 10 lac rupees under various government scheme for the development of his institute. 